\title{
KONVERSI AGAMA DI TINJAU DARI PERSFEKTIF KECERDASAN KOGNITIF DAN BERFIKIR KRITIS
}

\author{
Eddy Saputra \\ Teknik Informatika Universitas Indraprasta PGRI \\ Email: saputra2578@gmail.com
}

\begin{abstract}
abstrak
Perubahan dalam dalam bentuk apapun adalah sebuah keniscayaan, baik disengaja ataupun tidak disengaja, baik dikaitkan dengan campur tangan tuhan ataupun karena usaha yang keras dari manusianya. Perubahan juga sering terjadi pada keyakinan atau sering disebut dengan konversi pada agama. Dalam penelitian ini yang akan dibahas adalah perubahan dari agama non muslim menjadi agama Islam, perubahan ini sering kali dimulai dari sikap kritis yang mengandalkan kecerdasan kognitif, berawal dari sebuah pencarian dimana pada agama lama banyak hal yang kadang dianggap tidak masuk akal serta mulai mengaitkan jika agama harus mampu diterima oleh logika manusia. Mulailah mencari sebanyakbanyak informasi agar dapat membuat perbandingan antar agama yang lama dengan agama yang akan dituju sehingga pada akhirnya diambillah sebuah keputusan. Tulisan ini menggunakan metodologi kualitatif dan studi pustaka, ada beberapa nara sumber yang dijadikan data karena terlibat langsung dalam terjadinya konversi agama sebagai penguat data. Tujuan penelitian ini memberikan informasi bahwa perubahan harus dilakukan berdasarkan pengetahuan yang bersumber pada kecerdasan kognitif dan berfikir kritis, sehingga hasilnya dapat dipertanggung jawabkan.
\end{abstract}

Kata kunci : Konversi agama, Kecerdasan Kognitif, Berfikir Kritis

\begin{abstract}
Changes in any kind is a certainty, either it is intentionally or unintentionally, by God intervention or human endeavour. Changes also often occur in belief or often called conversion in religion. This experiment will discuss a conversion from non moeslims to be moeslims. This conversion often starts with critical attitude that rely on cognitive intelligence, radiating from a search where in the prior religio, many things is considered unreasonable and begin to relate if religion must be accepted by human logic. Start looking for information as much as possible to make comparisons between prior religions with intended religion so that the decission can be made. This paper used a qualitative methodology and literature study, there were several sources used as data amplifier because they are directly involved in the conversion of religion. The purpose of this study is to provide information that conversion must be made based on knowledge originating from cognitive intelligence and critical thinking, so the results can be accounted for.

Keywords: Religious conversion Cognitive Intelligence, Critical Thinking
\end{abstract}

\section{PENDAHULUAN}

Agama merupakan sumber keyakinan yang melekat pada setiap individu pemeluknya, seringkali apabila ada tindakan yang mengaitkan agama pada perbuatan negatif maka spontan menjadi sebuah anggapan telah terjadi penistaan pada agama. Oleh karena beragama diperlukan sebuah kecerdasan dimana salah satunya adalah kecersan kognitif yang dapat menuntun pemeluknya pada perbuatan yang selaras dengan niali-nilai yang diajarkan pada agamal. Dalam pandangan Piaget, remaja secara aktif membangun dunia kognitif mereka Kekuatan pemikiran remaja yang sedang berkembang membuka cakrawala kognitif dan cakrawala sosial baru [1].

Menurut Ahamad Sulaiman dan Nandy Agustin Syakarofath, berpikir kritis dapat 
diartikan sebagai upaya seseorang untuk memeriksa kebenaran dari suatu informasi menggunakan ketersediaan bukti, logika, dan kesadaran akan bias. Mengingat kondisi sosial yang semakin kompleks dan kemajuan teknologi informasi, mendorong derasnya pertukaran informasi yang belum terverifikasi[2].

Berfikir kritis dengan mengedepankan kecerdasan kognitif dapat menegmbangkan temuan yang baru. Sesuatu yang baru terus digali demi ingin menemukan solusi yang jadi permasalahan. Ada sebagian ajaran pada agama lama sering dianggap tidak rasional, dengan berfikir kritis yang mendororng kecerdasan kognitif berupaya untuk menemukan jawaban-jawaban yang selalu jadi pertanyaan pada agama lama.

Dengan berfikir kritis para pencari jawaban mulai mencari dan mengadakan komparasi terhadap agama yang akan dijadikan tujuannya, dalam tulisan ini konversi yang akan dibahas adalah perpindahan dari agama non Islam menuju ke agama Islam. Kalaupun fakta di lapangan tidak menutup kemungkinan ada juga konversi yang terjadi justru sebaliknya. Akan tetapi sering kali ditemukan motivasi yang berbeda ketika perubahan yang dilakukan dari non Islam ke Islam dan dari Islam ke non Islam.

Terjadinya konversi pada agama tidak bisa dikatakan sederhana, ini menyangkut keyakinan serta kebiasan yang sudah terbawa sejak lahir dan begitu kuat melekat dalam kehidupan keluarga serta sosial yang memiliki dampak cukup luas. Konversi pada agama bisa terjadi biasanya melalui proses yang cukup panjang, pencarian informasi tentang agama yang akan dituju dalam hal ini adalah Islam harus melalui sumber yang benar-benar bisa di pertanggung jawabkan, serta jawaban-jawaban dari semua pertanyaan harus meyakinkan juga memuaskan.

Resiko besar sering kali dihadapi oleh orangorang yang akan melakukan konversi agama, keluarga selaku orang-orang terdekat perlahan bisa dipastikan akan meninggalkan, begitu juga lingkungan keagamaannya. Secera aspek sosial akan dikucilkan, oleh karena itu diperlukan mentalitas yang kuat dalam menghadapi itu semua.

Maraknya perubahan pada keyakinan tidak hanya terjadi di dalam negeri, banyak juga terjadi diluar negeri, apalagi akhir-akhir ini istilah radikalisme begitu sering disebutsebut. Dalam artikel yang dimuat Republika online dengan judul'Orang Barat tertarik masuk Islam puncaknya sejak 11 September. Mengapa di negara maju seperti Eropa dan Amerika Serikat sekarang banyak orang yang tergerak hatinya ingin mengkaji agama Islam? Fenomena ini terjadi setelah peristiwa 11 September. Bangsa yang berjaya dan maju sedang berbondongbondong masuk agama Islam [3].

Berangkat dari stigma ini barat seakan mau menyatakan jika ajaran Islam begitu lekat dengan tindak kekerasan. Media dengan masive memberitakan kejadian ini bahwa pelaku kekerasan adalah orang yang beragama Islam, seakan-akan pemberitaan tersebut adalah benar dimata orang yang tidak mengetahui informasi yang sebenarnya. Semakin sering media memberitakan kejadiaan tersebut, bagi orang yang menggunakan kecerdasan kognitifnya mulai berfikir kritis serta mencari tau apa yang sebenarnya. Agama merupakan hal sakral bagi siapaun, maka para pelaku konversi agama agar dapat bertanggung jawab sepenuhnya terhadap langkah yang sudah menjadi keputusannya. 


\section{METODE}

Penelitian menggunakan metode kualitatif dan studi pustaka. Pendekatan kualitatif dapat menghasilkan penjabaran atau uraian tentang perkataan, prilaku dan sikap dari individu atau kelompok masyarakat. Kemudian diamati sehingga dapat mengahasilkan sebuah kesimpulan dasar. Penelitian kulitatif bertujuan mendapatkan pemahaman yang umum terhadap keberadaaan yang terjadi di tengah masyarakat. penelitian kualitatif ini adalah ingin menjelaskan keadaan yang sebenarnya dibalik fenomena yang terjadi didalamanya secara rinci dan tuntas [4].

Metode yang digunakan dalam kajian ini menggunakan metode atau pendekatan kepustakaan (library research), Studi pustaka atau kepustakaan dapat diartikan sebagai rangkaian kegiatan yang berkaitan dengan metode pengumpulan data pustaka, membaca kemudian mencatat setelah itu mengolah bahan penelitian, Pertama, bahwa penulis atau peneliti langsung berhadapan dengan teks (nash) atau data angka, bukan dengan pengetahuan langsung dari lapangan. Kedua, data pustaka bersifat "siap pakai" artinya peniliti tidak terjun langsung kelapangan karena peneliti langsung berhadapan terhadap sumber data yang ada di perpustakaan. Ketiga, bahwa data pustaka umumnya adalah sumber sekunder, penegertiannya bahwa peneliti mendapatkan bahan atau data dari tangan kedua dan bukan data yang bersumber dari data pertama di lapangan. Keempat, bahwa kondisi data pustaka tidak dibatasi oleh runga dan waktu [5].

1. Menelaah serta mengekplorasi data yang ada seperti dari majalah, buku, Koran, jurnal buku serta media elektronik sebagai sumber pengumpulan data dan informasi yang dianggap berhubungan dengan penelitian ini.

2. Menggali informasi dari informan yang terlibat langsung dalam konversi beragama, untuk menguatkan sumber data yang sebelumnya

3. Trianggulasi dibutuhkan dalam upaya pemeriksaan keabsahan data guna kesempurnaan, validitas data, keakuratan informasi, dan originalitas sumbersumber dalam sebuah penelitian kualitatif[6].

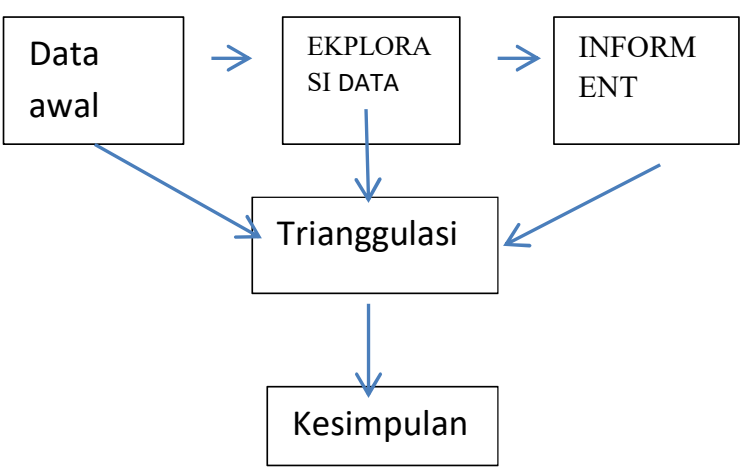

HASIL DAN PEMBAHASAN

A. Jasmine: Perilaku Luhur Muslim Pikat Aku Masuk Islam

Dikutip melalui rebpublika,co,id dalam tajuk khazanah mualaf Kamis 05 Des 2019 08:54 WIB. Jasmine, panggilan mojang Bandung yang kini tengah menyelesaikan sekolah desainnya di Jepang. Usianya genap 23 tahun pada 20 November lalu, tak dinyana kini telah menjadi Muslimah, cantik dengan jilbabnya.

Jasmine mengakui bahwa dia tidak memiliki keyakinan agama apapun. Karena memiliki lingkungan keluarga Katolik, hanya sebuah rutinitas saja Akhlak Muslim yang baik dia lihat secara 
nyata melalui teman pria yang dekat dengannya. Dia merupakan orang Arab asal dari Suriah. "Dia orang paling sabar yang pernah saya temui sejauh ini. Saya cinta sama karakter dia dan kasih sayang dia ke keluarganya. Dan saya tahu dia orangnya begitu karena hubungan dia dengan Allah dekat. Dia rajin shalat berjamaah ke masjid dan menjalankan puasa," kisahnya.

Akhlak temen Muslimnya yang sesuai dengan ajaran Islam tersebut, justru membuatnya iri. Karena dia selalu bisa bersikap baik dan sabar dalam menghadapi setiap masalah.untuk pergi ke gereja. Meski demikian, dia tetap menjalani ritual keagamaan hingga SMA [7]

Inilah kisah konversi agama yang dialami oleh Jasmine. Jasmine remaja asal kota bandung yang sedang meyelesaikan studinya di Jepang. Jasmine tertarik mempelajari Islam berangkat dari kekosongan jiwanya, dia memiliki agama akan tetapi seolah tidak punya agama. Bertemunya dia dengan seorang muslim yang begitu kuat mengamalkan serta menjalankan ajaran Islam membuat Jasmine menjadi tertarik untuk mempelajari Islam.

Tujuan Rasulullah di utus yang menjadi tugas utama memamngnya untuk memperbaiki akhlak masyarakat jahiliyah ketika itu, sebagaimana dalam sebuah ayat yang terdapat dalam al quran

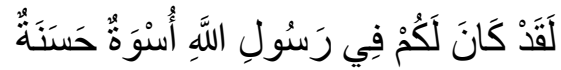

Sesungguhnya telah ada pada (diri) Rasulullah itu suri teladan yang baik. (QS al ahzab,21)
Sesungguhnya sumber akhlak yang paling utama adalah agama, karena akhlak merupakan cerminan dari keadaan keimanan yang terpantul dalam kehidupan sehari-hari. Agama dalam membina akhlak manusia dikaitkan dengan ketentuan hukum agama yang sifatnya pasti dan jelas. Ketentuan tersebut dijelaskan secara rinci di dalam agama. Olehnya itu, pembinaan akhlak tidak dapat dipisahkan dari agama [8].

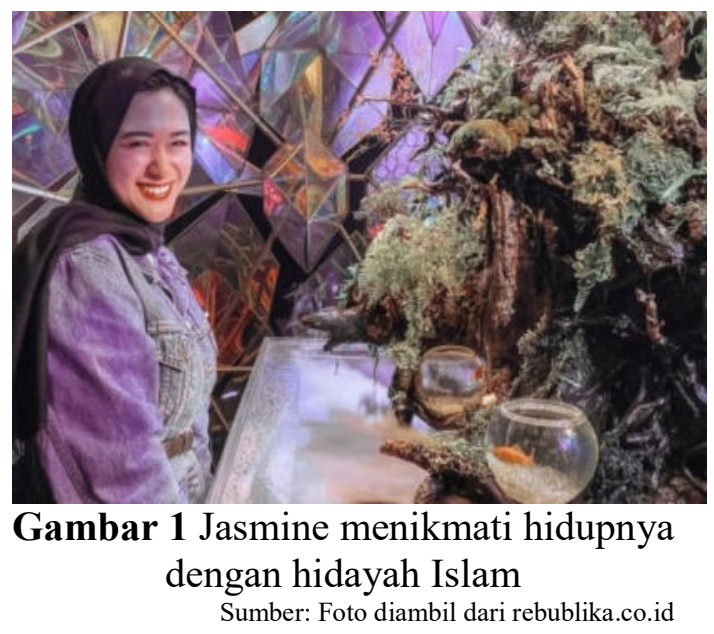

\section{B. Komedian Mualaf AS: Islam Ajarkan Cinta Orang Lain \\ REPUBLIKA.CO.ID, BRADFORD -} Komedian asal St Louis, Missouri, Amerika Serikat, Azeem Muhammad, berbicara soal Islam dan arti cinta yang sesungguhnya. Menurutnya, Islam adalah soal menemukan kesamaan satu sama lain, sebagai wujud untuk menjauhkan kepentingan pribadi.[9] 


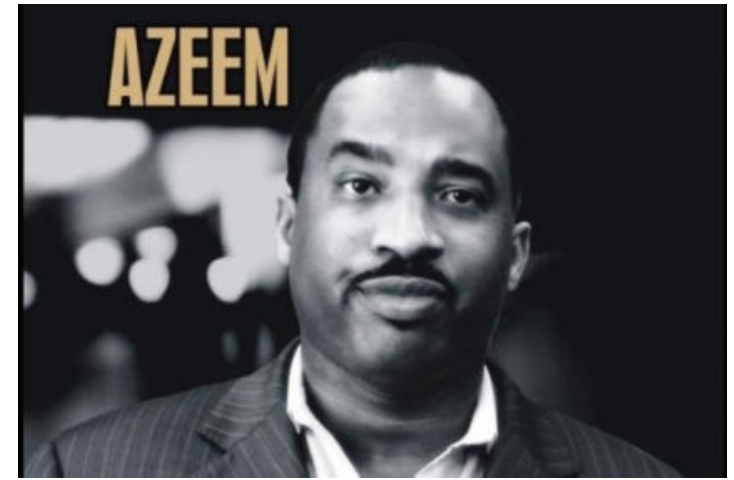

Gambar 2 Azeem Muhammad

Sumber: Foto diambil dari rebublika.co.id

Kebersamaan merupakan sumber rahmat dari Allah swt., karena rahmatNya hanya terdapat pada mereka yang menyebarkan rahmat di muka bumi. Mereka dapat membangun hidup dengan kebersamaan jika tidak ada kebencian dan kecemburuan dalam dada mereka, yang ada hanyalah kasih sayang di antara mereka. Kebersamaan akan melahirkan kebaikan-kebaikan sebagai implikasi dari saling menghormati, saling membantu, saling merasakan dan saling menghargai di antara anggota masyarakat.[10]

Kebersamaan dibangun Rasulullah ditengah masyarakat yang beragam dalam kota madinah, ajaran Islam menyatukan mereka dalam bingkai perssaudaraan, persaudaraan dalam bidang akidah yang disebut ukhuah Islamaiyah, persaudaraan sebangsa yang disebut ukhuah wathoniah dan ukhuah dalam kontek kemanusian, yang disebut ukhuah insaniah. Seyognyanya sebagai umat islam mampu mengaktualisasikan nilai-nilai persaudaran yang diajarkan Islam ditengah-tengah gencarnya teknologi yang berpotensi menjadikan eksklusifitas yang tidak bisa dihindari dalam kehidupan manusia.

\section{Kristo Paulus, mengritisi eksistensi Tuhan}

Pria kelahiran Cilacap bagian selatan 36 tahun yang lalu ini menuturkan kisahnya dalam proses konversi agama yang ia lakukan ketika masih duduk dibangku SMK. Sejak kecil lekat dengan ajaran katolik dalam lingkunagan keluarganya ketika dibangku SMK Kristo memberanikan diri untuk bertanya tentang eksistensi tuhan yang awalnya ia yakini, semakin sering pertanyaan itu dia ajukan semakin tidak yakin dengan keberadaaan tuhan yang ia yakini [11].

Bagaimana mungkin tuhan yang dia yakini sebagai manusia peyampai risalah tapi dia juga sebagai Tuhan yang Dzat, Begitu selalu hatinya bertanya. pada akhirnya Kristo mengalami kekosongan dalam hantinya. Dalam keadaan Kosong dia berusaha mencari pembenaraan di luar agama yang diyakini ketika itu. Lingkungan sekolah yang mayoritas Islam, Pada akhirnya Kristo tidak merasa kesulitan untuk bertanya tentang Islam dengan coba membandingkan konsep ketuhan antara agama lamanya dengan agama Islam.[12]

Saat tulisan ini dibuat Kristo mengajar di Sekolah Dasar Negeri dikawasan Jakarta dan sedang menempuh Stusi S3 dikampus Islam swasta di Jakarta. Konversi agama dari objek yang ada pada tulisan ini bermula dari memaksimalkan kecerdasan kognitif serta berfikir kritis pada keyakinan yang lama, dikarenakan banyak hal yang dianggap tidak rasional sehingga perlu digali lebih jauh, ketika semakin dalam dikaji yang terjadi malah semakin merasa tidak yakin pada agama lamanya. 
Memaksimalkan potensi berfikir untuk mencari jawaban atas keraguan yang ada pada diri orang-orang yang memutuskan untuk melakukan konversi agama. Semakin dalam mengkritisi keyakinan agama yang lama semakin tidak yakin, pemahamannya semakin dianggap tidak masuk akal. Sehingga perlu sebuah pembanding dan pada akhirnya mulai mencari agama yang dianggapnya logis, setelah melalui proses pemikiran yang panjang pada akhirnya keputusan pun diambil untuk menentukan Islam sebagai pilihan agama barunya.

\section{Pendidikan Pilar Kecerdasan Kognitif}

Lembaga pendidikan menjadi salah pilar untuk melatih bahkan mengahasilkan manusia cerdas. Konsep pendidikan yang mengasah kognitif melatih para siswa untuk berfikir krtitis dalam segala hal. Leterasi yang dibangun dalam dunia pendidikan memungkinkan sekali membuat seseorang berfikir di luar kebiasannya, termasuk yang berkaitan dengan terjadinya dalam perpindahan keyakinan pada seseorang

\section{SIMPULAN}

Agama merupakan prinsip yang sangat penting dalam setiap individu manusia. Agama juga merupakan identitas, maka tidak salah kalo banyak orang yang mempertanhkan agamanya demi identitasnya, dan ini ada dalam agama apapun. Akan tetapi perjalanan hidup yang dinamis meniscayakan terjadinya sebuah perubahan, baik yang disengaja ataupun memang harus dirubah karena kondisi dan keadaan. Hal ini juga bisa terjadi pada agama, lingkungan keluarga dekat akan menentukan agama seseorang. Seiring perjalanan waktu banyak orang yang memaksimalkan kecerdasan kognitif serta berfikir kritis terhadap agama yang dianut.
Semakin kritis semakin merasa tidak yakin dengan agama yang lama dan pada akhirnya mulai mencari jawaban atas ketidakyakinannya itu. Islam menjadi pilihan terhadap keraguan itu karena menurut para pelaku konversi agama, Islam memiliki pemahaman yang logis serta rahmatan lil alamin, beruat baik pada siapapun, dan tidak ada satupun ajarannnya untuk menebar kebencian apalagi dendam, sekalipun itu terhadap orang yang berbeda keyakinan.

\section{UCAPAN TERIMA KASIH}

Terima kasih saya ucapkan kepada Bapak Kristo Paulus yang sekarang bernama Ahmad Hidayat yang telah bersedia diwawancara prihal perjalannan dalam melakukan konversi agama yang beliau lakukan serta untuk memperkuat data dalam tulisan ini.

\section{DAFTAR PUSTAKA}

[1] Yessy Nur Endah Sary, Perkembangan Kognitif dan Emosi Psikologi Masa Remaja Awal, Jurnal Pengabdian Kepada Masyarakat Volume 1, No. 1, Mei 2017: Page 6-12 ISSN: 2579-7905

[2] Ahmad Sulaiman \& Nandy Agustin Syakarofath, Berpikir Kritis: Mendorong Introduksi dan Reformulasi Konsep dalam Psikologi Islam, Jurnal Buletin Psikologi ISSN 0854-7106 2018, Vol. 26, No. 2, $86-96$

[3] Republika.co.id. Khazanah, Mengapa Orang Barat Banyak yang Tertarik Masuk Islam, Kamis 21 Nov 2019 04:50 WIB

[4] Eddy Saputra, Alternatif pendidikan non formal dalam meningkatkan akhlak pada anak melalui pendidikan berbasis masjid, Jurnal SAP Unindra 2019

[5] Supriyadi, COMMUNITY OF PRACTITIONERS : SOLUSI ALTERNATIF BERBAGI PENGETAHUAN 
PUSTAKAWAN, Jurnal Lentera Pustaka 2 (2): 83-93, 2016 Copyright (C2016, ISSN: $2302-4666$ print/ 2540-9638

[6] Moleong J lexy, Metode Penelitian Kualitatif, Edisi Revisi, Cetakan ke 13 Bandung, Remaja Rosdakarya, 2013

[7] Republika.co.id. Khazanah, Perilaku Luhur Muslim Pikat Aku Masuk Isla, Kamis 05 Des 2019 08:54 WIB

[8] Munirah, Ahklak Dalam Persfektif Pndidikan Islam, AULADUNA: Jurnal Pendidikan Dasar Islam Vol. 4 No. 2, December 2017, pp. 39-47 p-ISSN: 2407-2451
[9] Republika.co.id. Khazanah, Komedian Mualaf AS: Islam Ajarkan Cinta Orang Lain Rabu 13 Nov 2019 05:00 WIB

[10]La Ode Ismail Ahmad, Indahnya Kebersamaan, Jurnal Diskursus Islam, Volume 06 Nomor 2, Agustus 2018

[11] Wawancara, Kristo Paulus, 14 Desember 2019

[12] Wawancara, Kristo Paulus, 14 Desember 2019. 